\title{
Prediction of phenprocoumon maintenance dose and phenprocoumon plasma concentration by genetic and non-genetic parameters
}

\author{
Christof Geisen - Beate Luxembourg - Matthias Watzka • Stefan W. Toennes • \\ Katja Sittinger • Milka Marinova • Nicolas von Ahsen • Edelgard Lindhoff-Last • \\ Erhard Seifried • Johannes Oldenburg
}

Received: 13 August 2010 / Accepted: 31 October 2010 /Published online: 26 November 2010

(C) Springer-Verlag 2010

\begin{abstract}
Purpose The anticoagulation response to vitamin $\mathrm{K}$ antagonists is characterised by high inter-individual variability. The impact of single nucleotide polymorphisms (SNPs) in several genes of enzymes involved in
\end{abstract}

Christof Geisen and Beate Luxembourg contributed equally to this work

C. Geisen $\cdot$ B. Luxembourg $\cdot$ K. Sittinger $\cdot$ E. Seifried $\cdot$

J. Oldenburg

German Red Cross, Institute of Transfusion Medicine and

Immunohaematology, University Hospital Frankfurt,

Frankfurt, Germany

B. Luxembourg $\cdot$ E. Lindhoff-Last

Department of Internal Medicine, Division of Vascular Medicine and Haemostaseology, University Hospital Frankfurt,

Frankfurt, Germany

M. Watzka $\cdot$ M. Marinova $\cdot$ J. Oldenburg

Institute of Experimental Haematology and Transfusion Medicine,

University Hospital Bonn,

Bonn, Germany

S. W. Toennes

Institute of Legal Medicine, University Hospital Frankfurt,

Frankfurt, Germany

N. von Ahsen

Department of Clinical Chemistry, University of Göttingen,

Göttingen, Germany

J. Oldenburg $(\square)$

Institute of Experimental Haematology and Transfusion Medicine,

University Clinic Bonn,

Sigmund-Freud-Strasse 25,

Bonn, Germany

e-mail: johannes.oldenburg@ukb.uni-bonn.de the vitamin $\mathrm{K}$ cycle on phenprocoumon dose variability and phenprocoumon plasma concentrations is still under investigation.

Methods We assessed the influence of VKORC1 c.$1639 \mathrm{G}>\mathrm{A}, C Y P 2 C 9 * 2, C Y P 2 C 9^{*} 3, C Y P 4 F 2$ c.1297G $>\mathrm{A}$, $C A L U$ c. ${ }^{*} 4 \mathrm{~A}>\mathrm{G}, E P H X 1$ c. $337 \mathrm{~T}>\mathrm{C}, G G C X$ c. $214+597 \mathrm{G}>\mathrm{A}$, $F 7$ c. $-402 \mathrm{G}>\mathrm{A}, F 7$ c. $-401 \mathrm{G}>\mathrm{T}, P R O C$ c. $-228 \mathrm{C}>\mathrm{T}$ and $P R O C$ c. $-215 \mathrm{G}>\mathrm{A}$ along with clinical and demographic parameters on steady-state phenprocoumon therapy in 75 patients. A prediction model was developed for total phenprocoumon plasma concentrations and daily phenprocoumon doses required for therapeutic anticoagulation.

Results The VKORC1 c.-1639 genotype was the main predictor of the phenprocoumon daily dose (adjusted $\mathrm{R}^{2}=37.6 \%$ ) and the total phenprocoumon concentration (adjusted $\mathrm{R}^{2}=38.3 \%$ ). CYP2C9 affected the phenprocoumon concentration, but not the dose requirements. SNPs in the other genes of the vitamin $\mathrm{K}$ cycle, concomitant medication, nicotine use and alcohol consumption did not predict phenprocoumon concentrations and phenprocoumon dose requirements in a multiple linear regression model. Phenprocoumon concentrations were predicted by VKORC1 c.-1639, CYP2C9 genotype, age and BMI. The final prediction model for the daily phenprocoumon dose requirements comprised $V K O R C 1$ c.-1639 genotype, age and height accounting for $48.6 \%$ of the inter-individual variability.

Conclusions A rough prediction of phenprocoumon maintenance doses can be achieved by a limited set of parameters (VKORC1, age, height). The investigated SNPs in CYP4F2, CALU, EPHX1, GGCX, F7, and PROC did not improve the predictive value of a pharmacogenetic-based dosing equation for phenprocoumon. 
Keywords Phenprocoumon - Dosing algorithm · VKORC1 C CYP2C9 - Vitamin K cycle

\section{Introduction}

Coumarins are effective for the primary and secondary prevention of venous thrombosis and arterial thromboembolism; however, they are one of the most common causes of serious adverse drug events [1,2]. Therapy with coumarins is characterised by a narrow therapeutic range, high inter-individual differences in dose response, and a considerable risk of a wide range of clinically relevant drug interactions. Inappropriate dosing of coumarins is associated with a substantial risk of both recurrent thromboembolism from under-anticoagulation and bleeding from overanticoagulation [3, 4].

A number of demographic, clinical and genetic factors have been shown to influence the anticoagulant effect of coumarins [4]. Furthermore, factors such as compliance, intercurrent diseases/infections and lifestyle factors, including physical activity and diet, may influence dose demands of coumarins. Coumarins exert their anticoagulant effects by inhibition of the vitamin K epoxide reductase complex subunit 1 (VKORC1), which converts vitamin K epoxide to vitamin K [5]. Vitamin $\mathrm{K}$ is an essential cofactor for post-translational gamma-carboxylation, which is required for the maturation of vitamin K-dependent clotting factors [6]. A single functional SNP in the promoter of the VKORC1 gene, VKORC1 c.-1639G $>$ A, affecting VKORC1 gene expression, has been shown to be a major determinant of coumarin dose variability, accounting for $13-49 \%$ of dose response [7-9]. Two common allelic variants of cytochrome P450 2C9, $C Y P 2 C 9^{*} 2$ and $C Y P 2 C 9^{*} 3$, which are associated with a markedly reduced capacity of CYP2C9 to metabolise coumarins (and thus extended plasma half-life), have also been shown to influence coumarin dose requirements [6].

Genotype-guided dosing has received increasing attention as a potentially useful strategy to improve the efficacy and safety of coumarins. Pharmacogeneticallyguided dosing formulas have been developed to predict the coumarin maintenance dose $[10,11]$. Most of these studies focussed on warfarin, the most widely used coumarin worldwide. However, dose prediction models developed for warfarin are not applicable to phenprocoumon, a coumarin derivate preferentially used in some European countries [12]. Phenprocoumon differs from warfarin in both pharmacokinetic and pharmacodynamic aspects [13]. While warfarin is predominantly metabolised by $\mathrm{CYP} 2 \mathrm{C} 9$, this enzyme plays a less significant role in the clearance of phenprocoumon, as this substance is alternatively metabolised by CYP3A4, and a significant proportion of unchanged phenprocoumon is excreted renally $[12,14,15]$. Moreover, several studies reported an impact of SNPs in genes of other vitamin $\mathrm{K}$ cycle components, e.g. calumenin (CALU), $C Y P 4 F 2$, microsomal epoxide hydrolase 1 (EPHX1), factor VII (F7), $\gamma$-glutamyl carboxylase $(G G C X)$ and protein $\mathrm{C}$ $(P R O C)$, on warfarin dose response [16-28]. Data concerning the effects of these genes on phenprocoumon maintenance dose requirements are very limited [29]. Therefore, the aim of our study was to investigate the impact of SNPs in these genes (VKORC1 c.-1639G $>\mathrm{A}$, CYP2C9 *2, CYP2C9 *3, CYP4F2 c. $1297 \mathrm{G}>\mathrm{A}, C A L U$ c. $* 4 \mathrm{~A}>\mathrm{G}, \quad E P H X 1 \quad$ c. $337 \mathrm{~T}>\mathrm{C}, \quad F 7 \quad$ c. $-402 \mathrm{G}>\mathrm{A}, \quad F 7$ c. $-401 \mathrm{G}>\mathrm{T}, G G C X$ c. $214+597 \mathrm{G}>\mathrm{A}, P R O C \quad$ c. $-228 \mathrm{C}>\mathrm{T}$ and $P R O C$ c. $-215 \mathrm{G}>\mathrm{A}$ ) on the phenprocoumon steadystate dose and to develop a formula to predict the effective phenprocoumon maintenance dose. Because the effect of genetic variants on the pharmacodynamics and pharmacokinetics might differ, we also investigated the effect of SNPs in these genes on total phenprocoumon plasma concentrations.

\section{Materials and methods}

Outpatients with a stable maintenance phase of phenprocoumon therapy were recruited over a period of 15 months from the anticoagulation clinic of the Division of Angiology and Haemostaseology of the University Hospital of Frankfurt, Germany. A target INR range of 2.0-3.0 was the prerequisite for study participation. Stable maintenance phase was defined as $\leq 25 \%$ change in phenprocoumon weekly dose to reach the target INR range $\pm 10 \%$ for at least three consecutive anticoagulation clinic visits with at least 14 days between subsequent visits. A total of 75 patients aged 19-92 years were included. Information on age, sex, weight, height, smoking habits, alcohol consumption, indication for anticoagulation, and concomitant medication including alternative agents were collected by a standardised questionnaire. Data regarding phenprocoumon doses were obtained from medical records and patients' phenprocoumon identification cards. Non-fasting venous blood samples were taken between 7:30 and 9:00 a.m. for the determination of the international normalised ratio (INR), plasma concentrations of phenprocoumon, and for DNA analysis. All patients were advised to take the total daily phenprocoumon dose in the evening. The study was approved by the local ethics committee, and all patients gave their written informed consent to participate in the study.

Laboratory methods

Blood was collected into Sarstedt Monovette tubes (Sarstedt, Nümbrecht, Germany) in 0.1 volume $0.106 \mathrm{~mol} / \mathrm{l}$ trisodium 
citrate for determination of the INR. For DNA analysis and measurement of phenprocoumon concentrations, the blood was collected into Sarstedt Monovette tubes containing $1.6 \mathrm{mg} / \mathrm{ml}$ EDTA. Plasma from citrate- and EDTAanticoagulated blood samples was prepared by centrifugation at $2,500 \times \mathrm{g}$ for $15 \mathrm{~min}$ within $0.5 \mathrm{~h}$ of the blood draw. The INR was determined using the thromboplastin reagent STA Neoplastin Plus (Roche, Mannheim, Germany) on the automated coagulation analyser STA (Roche) within $1 \mathrm{~h}$ of the blood draw. For determination of the phenprocoumon plasma concentration plasma aliquots were immediately frozen and stored at $-70^{\circ} \mathrm{C}$ until assay performance in series.

Total phenprocoumon plasma concentrations were determined after precipitation with hexobarbitone as the internal standard, using liquid chromatography coupled with timeof-flight mass spectrometry. Fifty microlitres of EDTA plasma were precipitated and vortexed with $200 \mu$ of acetonitrile containing hexobarbitone $(2.5 \mathrm{ng} / \mu \mathrm{l})$. After centrifugation, the supernatant was transferred into autosampler vials. The analysis of $2 \mu \mathrm{l}$ was performed using an Agilent 1100 series liquid chromatograph interfaced to an Agilent 1100 series oa-TOF system (Waldbronn, Germany) operated in negative electrospray ionisation mode (ESI) with $10 \mathrm{~L} / \mathrm{min}$ nitrogen flow at $350^{\circ} \mathrm{C}$ and $3 \mathrm{kV}$ capillary voltage. Data acquisition was performed in a mass range from $\mathrm{m} / \mathrm{z} 100$ to 1,100 with simultaneous internal mass calibration in each recorded spectrum (system reference mixture supplied by the Agilent dual-sprayer interface, $\mathrm{m} / \mathrm{z}$ 112.9856 and $\mathrm{m} / \mathrm{z} 1033.9881$ ). Chromatographic separation was achieved on a $100 \times 2.0$-mm Polaris C18-Ether $3-\mu \mathrm{m}$ column (Varian, Darmstadt, Germany) at $50^{\circ} \mathrm{C}$ using a gradient of acetonitrile $/ 0.05 \%$ acetic acid $(30 \%$ acetonitrile for $0.5 \mathrm{~min}$ and increased to $85 \%$ in $3.5 \mathrm{~min}$ followed by $100 \%$ wash and re-equilibration) at $0.4 \mathrm{ml} / \mathrm{min}$ over a total run time of $10 \mathrm{~min}$. Identification of phenprocoumon was based on retention time and confirmation of accurate phenprocoumon mass with at least two isotopes ( $\pm 3 \mathrm{ppm})$. For the quantitative assay, a linear calibration curve was prepared from phenprocoumon spiked into drug-free plasma over the range of therapeutic concentrations (up to $5 \mathrm{mg} / \mathrm{l}$ ) [30]. The within- and between-day precisions at the lower limit of quantitation $(0.5 \mathrm{mg} / \mathrm{l})$, at $1 \mathrm{mg} / \mathrm{l}$ and $5 \mathrm{mg} /$ 1 were less than $7 \%$ ( $n=6$ each).

\section{Genetic analyses}

Genomic DNA was prepared from buffy coats of the EDTA blood samples by standard procedures. DNA samples were analysed for SNPs (see Table 2) in the genes VKORC1, $C Y P 2 C 9, C A L U, E P H X 1, F 7$ and $G G C X$ as described in a separate publication [31]. Amplification of the genes of PROC and CYP4F2 were performed in a similar manner, except that an annealing temperature of $60^{\circ} \mathrm{C}$ was used.
Genotyping for the CYP4F2 c. $1297 \mathrm{G}>\mathrm{A}$ polymorphism in exon 11 and the $P R O C$ c. $-228 \mathrm{C}>\mathrm{T}$ and $P R O C$ c. $-215 \mathrm{G}>\mathrm{A}$ promoter polymorphisms was performed by sequencing with the following primers: $C Y P 4 F 2$, forward 5'GTCTCCTGGGTAGGAAGAG-3', reverse 5' GTTGTGTGTGTCTTTGAG-3', PROC, forward 5'-GGG GCTAAAATGAGACCACA-3', reverse 5'-AGGCC TCCCTCTCCATAGAC-3'.

\section{Definitions}

The daily phenprocoumon dose was calculated by the weekly phenprocoumon dose before blood collection divided by 7 . The body mass index (BMI) was calculated from each patient's self-reported height and weight $\left(\mathrm{kg} / \mathrm{m}^{2}\right)$. The body surface area (BSA) was calculated using the formula $0.007184 \times$ height in $\mathrm{cm}^{0.725} \times$ weight in $\mathrm{kg}^{0.425}$. According to their product information, drugs were categorised into drugs not known to interfere with phenprocoumon, drugs that potentiate and drugs that attenuate phenprocoumon pharmacokinetics. According to concomitant drug use, patients were categorised as:

1. Patients not using concomitant drugs

2. Patients using only drugs not known to interfere with phenprocoumon

3. Patients using potentiating but no attenuating drugs

4. Patient using attenuating drugs but no potentiating drugs

5. Patients using both potentiating and attenuating drugs

Based on the reports of the frequency of alcohol intake per week, alcohol consumption was classified into four categories: no report of alcohol habits, $0-1,2-5$ and $>5$ drinks per week.

\section{Statistical analysis}

The Kolmogorov-Smirnov and Shapiro-Wilk tests were used to test variables for normality. Square root transformation of variables with a skewed distribution was performed to allow the application of parametric tests and regression analysis. Analyses of variance (ANOVA) and Student's $t$ tests were used to compare the daily phenprocoumon doses and phenprocoumon plasma concentrations among the different groups. Pearson's or Spearman's correlation analysis was performed to estimate the association between age, weight, height, BMI and BSA with regard to the daily phenprocoumon doses and phenprocoumon plasma concentrations. Multivariate linear regression analysis was performed to determine predictors of daily phenprocoumon doses and phenprocoumon plasma concentrations. Variables with a $p$ value $<0.1$ in the univariate analysis were entered into a stepwise multiple regression 
model. Dummy variables were used to code for the pharmacogenetic variables and the frequency of alcohol consumption in the multiple regression analysis. Continuous variables were used for age, height, weight, BMI and BSA.

Based on the regression equation, we calculated the predicted daily phenprocoumon dose for each patient and compared it with the actual recorded mean daily phenprocoumon dose. The association between the actual and calculated phenprocoumon doses was evaluated using Passing-Bablok regression analysis.

Based on the present sample size, the study had $80 \%$ statistical power to detect a difference of $0.43 \mathrm{mg}$ between the actual and the predicted daily phenprocoumon dose, using a two-sided one-sample $t$ test at the 0.05 significance level.

The software PASW Statistics 18 for Windows was used for all statistical analyses. Sample size calculation was performed with SPSS Sample Power 2.0. Values are given as the median and range or interquartile range, if not otherwise stated. A two-tailed $p$ value $<0.05$ was considered statistically significant. For practical reasons, in the tables and figures, the raw data instead of the square root transformed values are shown. In the figures, $p$ values for the comparison between groups were calculated with the Mann-Whitney $U$ test.

All SNPs were tested for deviations from the HardyWeinberg equilibrium using Fisher's exact test (http://ihg2. helmholtz-muenchen.de/cgi-bin/hw/hwa1.pl).

\section{Results}

The patient cohort was predominantly comprised of Caucasian patients, as is representative for this region. Females comprised $50.7 \%$ of study participants, and the most common indication for phenprocoumon therapy was a history of venous thromboembolism. Because most of the patients were referred to our centre due to severe or recurrent venous thromboembolism, the majority of patients $(87 \%)$ were on long-term anticoagulation ( $\geq 1$ year). Table 1 shows the baseline characteristics of the study population. Table 2 gives the allele frequencies of the investigated SNPs. All SNPs were in HardyWeinberg equilibrium (all $p>0.07$ ).

\section{Phenprocoumon dose}

The median daily phenprocoumon dose in the whole study cohort was $2.14 \mathrm{mg} /$ day with a wide inter-individual range $(0.75-4.50 \mathrm{mg} /$ day $)$. The daily phenprocoumon dose was significantly associated with VKORC1 c.-1639, EPHXI c.337 and PROC c.-228 genotype (Table 3). The largest dose differences were observed among VKORC1 genotypes
Table 1 Baseline characteristics of the study population. Values are given as median (range) unless stated otherwise

\begin{tabular}{|c|c|}
\hline Parameter & Value \\
\hline Number of patients, $n$ & 75 \\
\hline Caucasian, $n(\%)$ & $73(97.3)$ \\
\hline Black, $n(\%)$ & $2(2.7)$ \\
\hline Female, $n(\%)$ & $38(50.7)$ \\
\hline Age, years & $64(19-92)$ \\
\hline BSA, $\mathrm{m}^{2}$ & $1.88(1.44-2.75)$ \\
\hline Height, cm & $170(151-198)$ \\
\hline Weight, kg & $76(49-145)$ \\
\hline BMI & $26(18-40)$ \\
\hline INR & $2.5(1.8-3.25)$ \\
\hline $\begin{array}{l}\text { Daily phenprocoumon } \\
\text { dose, } \mathrm{mg} \text { /day }\end{array}$ & $2.14(0.75-4.50)$ \\
\hline $\begin{array}{l}\text { Total phenprocoumon plasma } \\
\text { concentration, } \mathrm{mg} / \mathrm{l}\end{array}$ & $1.93(0.72-5.10)$ \\
\hline \multicolumn{2}{|l|}{ Nicotine habits ${ }^{\mathrm{a}}$} \\
\hline User, $n(\%)$ & $9(12.2)$ \\
\hline Non-user, $n(\%)$ & $65(87.8)$ \\
\hline \multicolumn{2}{|l|}{ Alcohol consumption } \\
\hline Patients not reporting alcohol habits & $19(25.3)$ \\
\hline $0-1$ drink per week, $n(\%)$ & $22(29.3)$ \\
\hline $2-5$ drinks per week, $n(\%)$ & $22(29.3)$ \\
\hline$>5$ drinks per week, $n(\%)$ & $12(16.0)$ \\
\hline \multicolumn{2}{|l|}{ Concomitant medication } \\
\hline Patients with no concomitant drugs & $21(28.0)$ \\
\hline $\begin{array}{l}\text { Patients using only drugs not } \\
\text { known to interfere with phenprocoumon }\end{array}$ & $10(13.3)$ \\
\hline $\begin{array}{l}\text { Patients using potentiating }{ }^{\mathrm{c}} \text { but } \\
\text { no attenuating drugs }\end{array}$ & $28(37.3)$ \\
\hline $\begin{array}{l}\text { Patients using attenuating }{ }^{\mathrm{d}} \text { but } \\
\text { no potentiating drugs }\end{array}$ & $2(2.7)$ \\
\hline $\begin{array}{l}\text { Patients using both potentiating } \\
\text { and attenuating drugs }\end{array}$ & $14(18.7)$ \\
\hline \multicolumn{2}{|l|}{ Indication for anticoagulation, $n(\%)$} \\
\hline Venous thromboembolism ${ }^{\mathrm{e}}$ & $50(66.7)$ \\
\hline Atrial fibrillation ${ }^{\mathrm{e}}$ & $11(14.7)$ \\
\hline Heart valve replacement ${ }^{\mathrm{e}}$ & $4(5.3)$ \\
\hline Other or multiple indications ${ }^{\mathrm{e}}$ & $10(13.3)$ \\
\hline
\end{tabular}

BSA $=$ body surface area; $\mathrm{BMI}=$ body mass index; INR = international normalised ratio

a $n=74$

b e.g. captopril, atenolol

c e.g. amiodarone, simvastatin, L-thyroxin, allopurinol

d e.g. metformin, digitoxin, prednisolone

${ }^{\mathrm{e}}$ Target INR range of 2.0-3.0

(Fig. 1a). Compared with VKORC1 c.-1639GA carriers, the median daily phenprocoumon dose was $27.5 \%$ less in AA carriers and $44.6 \%$ higher in GG carriers. The phenprocoumon dose requirement was also negatively correlated with age 
Table 2 Allele frequencies of the investigated SNPs in the study cohort

\begin{tabular}{|c|c|c|c|c|c|c|}
\hline Gene & Location & cDNA position & $\begin{array}{l}\text { Amino acid } \\
\text { position }\end{array}$ & $\begin{array}{l}\text { Ref. SNP } \\
\text { number (rs) }\end{array}$ & $\begin{array}{l}\text { Allele } \\
\text { frequency }\end{array}$ & \\
\hline \multirow[t]{2}{*}{ VKORC1 } & Promoter & c. $-1639 \mathrm{G}>\mathrm{A}$ & - & rs9923231 & G & 0.62 \\
\hline & & & & & A & 0.38 \\
\hline \multirow[t]{4}{*}{ СYР2C9 } & Exon 3 & c. $430 \mathrm{C}>\mathrm{T}$ & p.Arg144Cys & rs1799853 & $\mathrm{C}$ & 0.87 \\
\hline & & & & & $\mathrm{T}$ & 0.13 \\
\hline & Exon 7 & c. $1075 \mathrm{~A}>\mathrm{C}$ & p.Ile359Leu & rs 1057910 & A & 0.94 \\
\hline & & & & & $\mathrm{C}$ & 0.06 \\
\hline \multirow[t]{2}{*}{ CYP4F2 } & Exon 11 & c. $1297 \mathrm{G}>\mathrm{A}$ & p.Val433Met & rs2108622 & G & 0.73 \\
\hline & & & & & A & 0.27 \\
\hline \multirow[t]{2}{*}{$C A L U$} & 3'UTR & c. $* 4 A>G$ & - & rs1043550 & A & 0.65 \\
\hline & & & & & G & 0.35 \\
\hline \multirow[t]{2}{*}{ EPHXI } & Exon 3 & c. $337 \mathrm{~T}>\mathrm{C}$ & p.Tyr113His & rs 1051740 & $\mathrm{~T}$ & 0.66 \\
\hline & & & & & $\mathrm{C}$ & 0.34 \\
\hline \multirow[t]{2}{*}{$F 7$} & Promoter & c. $-402 \mathrm{G}>\mathrm{A}$ & - & rs762637 & G & 0.83 \\
\hline & & & & & A & 0.17 \\
\hline \multirow[t]{2}{*}{$F 7$} & Promoter & c. $-401 \mathrm{G}>\mathrm{T}$ & - & rs7981123 & $\mathrm{G}$ & 0.84 \\
\hline & & & & & $\mathrm{T}$ & 0.16 \\
\hline \multirow[t]{2}{*}{$G G C X$} & Intron 2 & c. $214+597 \mathrm{G}>\mathrm{A}$ & - & rs 12714145 & G & 0.57 \\
\hline & & & & & A & 0.43 \\
\hline \multirow[t]{2}{*}{ PROC } & Promoter & c. $-228 \mathrm{C}>\mathrm{T}$ & - & rs1799808 & $\mathrm{C}$ & 0.67 \\
\hline & & & & & $\mathrm{T}$ & 0.33 \\
\hline \multirow[t]{2}{*}{ PROC } & Promoter & c. $-215 \mathrm{G}>\mathrm{A}$ & - & rs1799809 & G & 0.46 \\
\hline & & & & & A & 0.54 \\
\hline
\end{tabular}

( $r=-0.324, p=0.005$ ). Figure 2 illustrates that the median daily phenprocoumon dose was especially decreased during the 8th and 9th decade of life (median/range: 1.71/1.50-2.36 and $1.50 / 0.83-2.14$ respectively vs $2.79 / 1.82-3.64 \mathrm{mg}$ /day in individuals aged 19-50 years). The association between phenprocoumon dose requirements and height did not reach significance in the univariate analysis $(p=0.064)$.

Body weight $(p=0.309)$, BMI $(p=0.995)$, BSA $(p=$ 0.157), CYP2C9, CYP4F2 c.1297, CALU c.*4, F7 c.-402, F7 c. $-401, G G C X$ c. $214+597$, PROC c. -215 genotype, gender, smoking and alcohol habits, or concomitant medication did not significantly impact on phenprocoumon dose requirements (Table 3).

Combining VKORC1 c.-1639 genotype, height and age in the multiple linear regression analysis produced the best model for phenprocoumon dose prediction, explaining $48.6 \%$ of the daily phenprocoumon dose variability (Table 4).

The final dosing formula for the calculation of the daily phenprocoumon dose was: $\sqrt{\text { daily }}$ phenprocoumon dose $(\mathrm{mg})=0.460+0.238$ (VKORC1 c.-1639GG) -0.271 $($ VKORC1 c. $-1639 \mathrm{AA})+0.007$ (height in $\mathrm{cm})-0.004$ (age in years). In this regression equation, VKORC1 c.-1639AA and VKORC1 c.-1639GG were coded as 0 if absent and 1 if present. Because the dosing equation computes the square root of the daily phenprocoumon dose, the output must be squared to calculate the actual daily dose.

To estimate the predictive value of the dosing formula, we recalculated the daily phenprocoumon dose for each patient according to the regression equation (Fig. 3). The Passing-Bablok regression analysis indicated good correlation between the actual and the estimated daily phenprocoumon dose ( $r=0.701$, Fig. 3 ).

\section{Phenprocoumon concentration}

The median phenprocoumon concentration in the entire cohort was $1.93 \mathrm{mg} / \mathrm{l}$ and varied between 0.72 and $5.10 \mathrm{mg} /$ 1 (Fig. 1b). Of the different investigated SNPs, only VKORC1 and CYP2C9 genotypes were significantly associated with total phenprocoumon concentrations (Table 3). VKORC1 c.-1639A allele carriers were those with the lowest phenprocoumon concentrations, whereas $C Y P 2 C 9$ variant allele status was associated with higher total phenprocoumon plasma concentrations (Table 3).

There was a significant association between phenprocoumon concentrations and alcohol habits $(p=0.020)$ and a significant negative correlation between phenprocoumon concentrations and weight $(r=-0.259, p=0.025)$ and BMI $(r=-0.252, p=0.029)$. The association between phenprocoumon concentrations and age $(r=-0.226, p=0.051)$ and 
Table 3 Daily phenprocoumon doses and phenprocoumon plasma concentrations according to genotypes, demographic parameters, lifestyle factors and concomitant medication. Values are given as median (interquartile range)

\begin{tabular}{|c|c|c|c|c|c|}
\hline Parameter & $n$ & Daily phenprocoumon dose, $\mathrm{mg}$ & $p$ value* & Phenprocoumon concentration, $\mathrm{mg} / \mathrm{l}$ & $p$ value* \\
\hline \multicolumn{6}{|l|}{ VKORC1 c.-1639 } \\
\hline GG & 30 & $2.79(2.14-3.70)$ & & $2.29(1.98-2.91)$ & \\
\hline GA & 33 & $1.93(1.50-2.47)$ & & $1.85(1.53-2.28)$ & \\
\hline AA & 12 & $1.40(1.18-1.66)$ & $<0.001$ & $1.05(0.86-1.24)$ & $<0.001$ \\
\hline \multicolumn{6}{|l|}{ СУР2C9 } \\
\hline$* 1 / * 1$ & 48 & $2.14(1.50-2.79)$ & & $1.84(1.27-2.27)$ & \\
\hline$* 1 / * 2$ & 18 & $1.71(1.50-2.47)$ & & $2.02(1.60-2.63)$ & \\
\hline$* 1 / * 3$ & 8 & $2.25(1.64-3.81)$ & & $2.00(1.83-3.04)$ & \\
\hline$* 2 / * 2$ & 0 & - & & - & \\
\hline$* 2 / * 3$ & 1 & $2.14(2.14)$ & & $5.1(5.1)$ & \\
\hline$* 3 / * 3$ & 0 & - & 0.795 & - & $<0.001$ \\
\hline \multicolumn{6}{|l|}{ CYP4F2 c. 1297} \\
\hline GG & 37 & $2.36(1.71-3.11)$ & & $2.06(1.51-2.56)$ & \\
\hline GA & 36 & $1.82(1.50-2.52)$ & & $1.84(1.52-2.26)$ & \\
\hline $\mathrm{AA}$ & 2 & $1.82(1.50-1.82)$ & 0.221 & $1.86(1.45-1.86)$ & 0.472 \\
\hline \multicolumn{6}{|l|}{$C A L U$ c. $* 4$} \\
\hline AA & 28 & $2.14(1.55-2.79)$ & & $1.92(1.27-2.26)$ & \\
\hline $\mathrm{AG}$ & 41 & $2.14(1.50-2.79)$ & & $1.99(1.53-2.44)$ & \\
\hline GG & 6 & $2.90(2.17-3.75)$ & 0.197 & $1.90(1.54-3.25)$ & 0.735 \\
\hline \multicolumn{6}{|l|}{ EPHXI с. 337} \\
\hline $\mathrm{TT}$ & 35 & $2.25(1.71-3.00)$ & & $1.92(1.56-2.30)$ & \\
\hline $\mathrm{TC}$ & 29 & $2.14(1.56-2.79)$ & & $1.99(1.49-2.49)$ & \\
\hline $\mathrm{CC}$ & 11 & $1.71(1.39-2.14)$ & 0.033 & $1.62(1.17-2.48)$ & 0.767 \\
\hline \multicolumn{6}{|l|}{ F7 c. -402} \\
\hline GG & 53 & $2.14(1.5-2.79)$ & & $1.87(1.52-2.44)$ & \\
\hline GA & 20 & $2.14(1.55-3.16)$ & & $1.93(1.33-2.30)$ & \\
\hline $\mathrm{AA}$ & 2 & $2.04(1.71-2.04)$ & 0.891 & $1.92(1.81-1.92)$ & 0.870 \\
\hline \multicolumn{6}{|l|}{ F7 c. -401} \\
\hline GG & 50 & $2.20(1.66-3.05)$ & & $1.91(1.53-2.42)$ & \\
\hline GT & 25 & $1.93(1.50-2.47)$ & & $1.95(1.49-2.32)$ & \\
\hline $\mathrm{TT}$ & 0 & - & 0.193 & - & 0.367 \\
\hline \multicolumn{6}{|l|}{$G G C X$ c. $214+597$} \\
\hline GG & 26 & $2.14(1.66-2.63)$ & & $2.01(1.55-2.34)$ & \\
\hline GA & 34 & $2.14(1.50-2.84)$ & & $1.93(1.50-2.52)$ & \\
\hline AA & 15 & $2.25(1.61-3.21)$ & 0.835 & $1.82(1.47-2.30)$ & 0.808 \\
\hline \multicolumn{6}{|l|}{ PROC c. -228} \\
\hline $\mathrm{CC}$ & 32 & $2.36(1.93-3.16)$ & & $2.09(1.66-2.48)$ & \\
\hline $\mathrm{CT}$ & 36 & $1.71(1.50-2.79)$ & & $1.86(1.39-2.17)$ & \\
\hline $\mathrm{TT}$ & 7 & $1.50(1.18-2.14)$ & 0.018 & $1.61(0.74-2.64)$ & 0.275 \\
\hline \multicolumn{6}{|l|}{ PROC c. -215} \\
\hline GG & 16 & $2.79(1.77-3.56)$ & & $1.93(1.58-2.54)$ & \\
\hline GA & 37 & $2.14(1.50-2.68)$ & & $1.95(1.50-2.38)$ & \\
\hline $\mathrm{AA}$ & 22 & $1.71(1.50-2.47)$ & 0.072 & $1.90(1.48-2.40)$ & 0.939 \\
\hline \multicolumn{6}{|l|}{ Sex } \\
\hline Female & 38 & $2.14(1.71-3.00)$ & & $2.09(1.82-2.65)$ & \\
\hline Male & 37 & $2.14(1.50-2.79)$ & 0.735 & $1.65(1.29-2.22)$ & 0.008 \\
\hline \multicolumn{6}{|l|}{ Alcohol consumption } \\
\hline Patients not reporting alcohol habits & 19 & $2.14(1.50-2.36)$ & & $1.61(1.17-2.15)$ & \\
\hline $0-1$ drinks per week & 22 & $2.04(1.47-3.11)$ & & $1.90(1.50-2.48)$ & \\
\hline $2-5$ drinks per week & 22 & $2.68(1.88-3.40)$ & & $2.29(1.76-3.09)$ & \\
\hline$>5$ drinks per week & 12 & $1.82(1.55-2.33)$ & 0.060 & $1.72(1.49-2.07)$ & 0.020 \\
\hline
\end{tabular}


Table 3 (continued)

\begin{tabular}{|c|c|c|c|c|c|}
\hline Parameter & $n$ & Daily phenprocoumon dose, $\mathrm{mg}$ & $p$ value* & Phenprocoumon concentration, mg/l & $p$ value* \\
\hline \multicolumn{6}{|l|}{ Nicotine habits } \\
\hline Smoker & 9 & $1.93(1.50-3.00)$ & & $1.53(1.13-2.13)$ & \\
\hline Non-smoker & 65 & $2.14(1.56-2.79)$ & 0.485 & $1.95(1.58-2.39)$ & 0.124 \\
\hline \multicolumn{6}{|l|}{ Concomitant medication } \\
\hline No concomitant drugs & 21 & $2.14(1.71-3.16)$ & & $2.15(1.50-2.94)$ & \\
\hline Drugs not known to interfere with phenprocoumon & 10 & $2.47(1.66-3.05)$ & & $1.63(1.50-2.24)$ & \\
\hline Potentiating drugs, no attenuating drugs & 28 & $1.82(1.50-2.52)$ & & $1.92(1.19-2.30)$ & \\
\hline Attenuating drugs, no potentiating drugs & 2 & $1.77(1.39-1.77)$ & & $2.06(1.85-2.06)$ & \\
\hline Both potentiating and attenuating drugs & 14 & $2.31(1.66-3.54)$ & 0.380 & $1.93(1.72-2.47)$ & 0.346 \\
\hline
\end{tabular}

${ }^{*} p$ values for the overall comparison among the subgroups
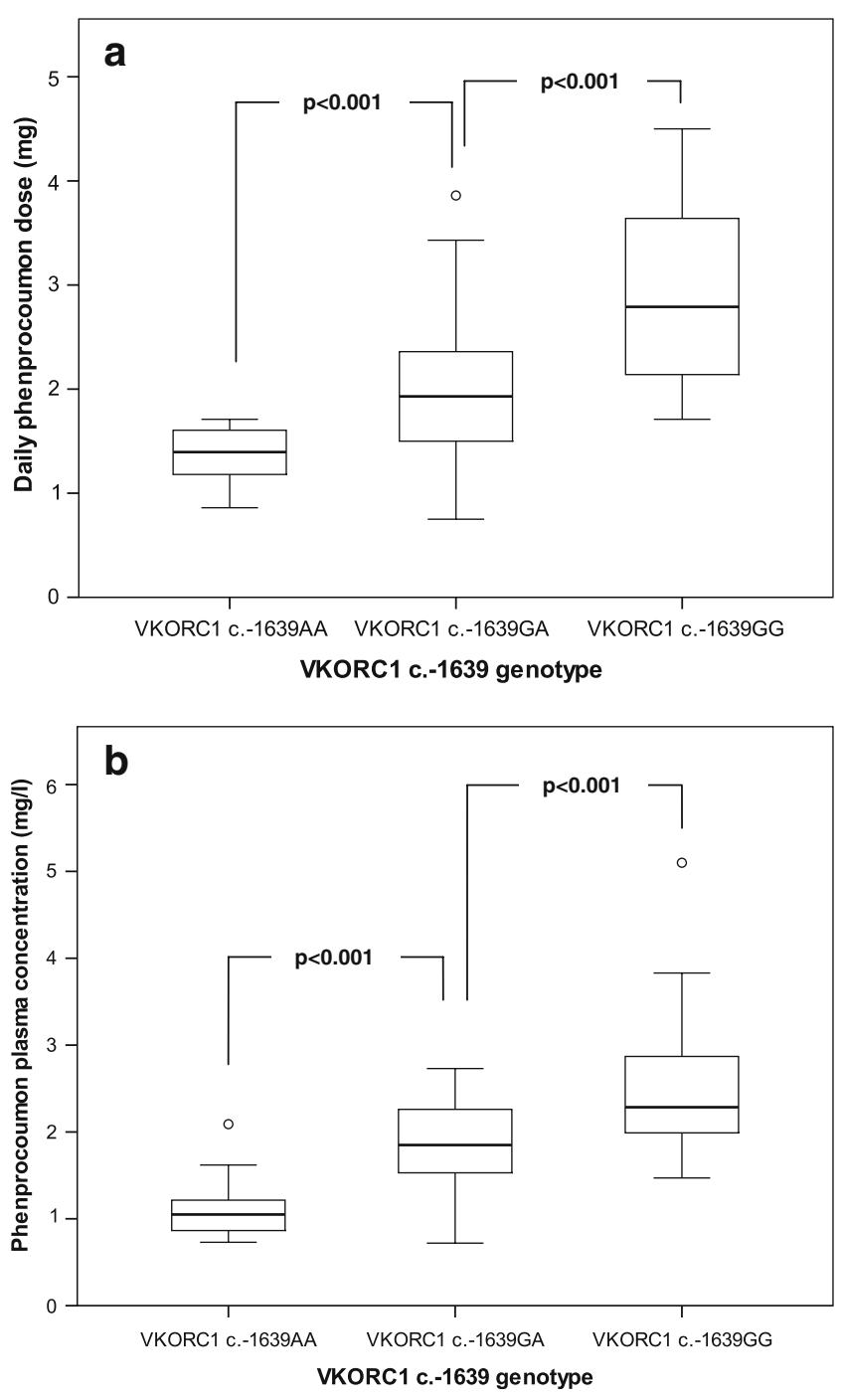

Fig. 1 a Daily phenprocoumon doses according to VKORC1 c.-1639 genotypes. The median daily phenprocoumon doses are depicted within the boxes. b Phenprocoumon plasma concentrations according to $V K O R C 1$ c.-1639 genotypes. The median daily phenprocoumon plasma concentrations are depicted within the boxes. In $\mathbf{a}$ and $\mathbf{b}$ the boxes end at the 25 th and 75 th percentiles. The whiskers extend to the farthest points that are not outliers. Outliers are depicted as open dots
BSA $(r=-0.219, p=0.059)$ did not reach statistical significance in the univariate analysis. No correlation was observed between phenprocoumon concentrations and height $(p=$ $0.517)$, nicotine habits and concomitant medication (Table 3 ).

The difference in phenprocoumon concentrations between women and men (Table 3) seemed to be due to the higher BMI values in men (BMI median/range: men 27/21-37, women: $25 / 18-40, p=0.019)$ because sex was not independently associated with phenprocoumon concentrations in the multivariate analysis.

In the multiple linear regression analysis, the $V K O R C 1$ c.-1639 and CYP2C9 genotype, age, and the square root of BMI were independently and significantly associated with the phenprocoumon plasma concentrations (Table 5). Comparable to the daily phenprocoumon dose, the VKORC1 genotype was found to be the most powerful predictor of phenprocoumon plasma concentrations, accounting for $38.3 \%$ of the observed inter-individual variability in phenprocoumon plasma concentrations (Table 5). The full model explained $52.8 \%$ of the variance of the phenprocoumon concentration (Table 5).

\section{Discussion}

In this study, we evaluated clinical parameters along with SNPs in eight genes including VKORC1, CYP2C9, $C Y P 4 F 2, C A L U, E P H X 1, F 7, G G C X$ and $P R O C$ to identify factors determining the total phenprocoumon plasma concentrations and phenprocoumon maintenance dose requirements in patients on stable phenprocoumon therapy.

About $53 \%$ of the variability of the total phenprocoumon concentration and $49 \%$ of the phenprocoumon dose variability could be explained by a pharmacogenetically based model. The largest part of variance was captured solely by $V K O R C 1$ c.-1639, which accounted for approximately $38 \%$ of the variability of the plasma concentration as well as the daily phenprocoumon dose. This is in line 
Fig. 2 Daily phenprocoumon doses in different age groups. Median doses are depicted within the boxes. The boxes end at the 25th and 75 th percentiles. The whiskers extend to the farthest points that are not outliers. Outliers are depicted as open dots

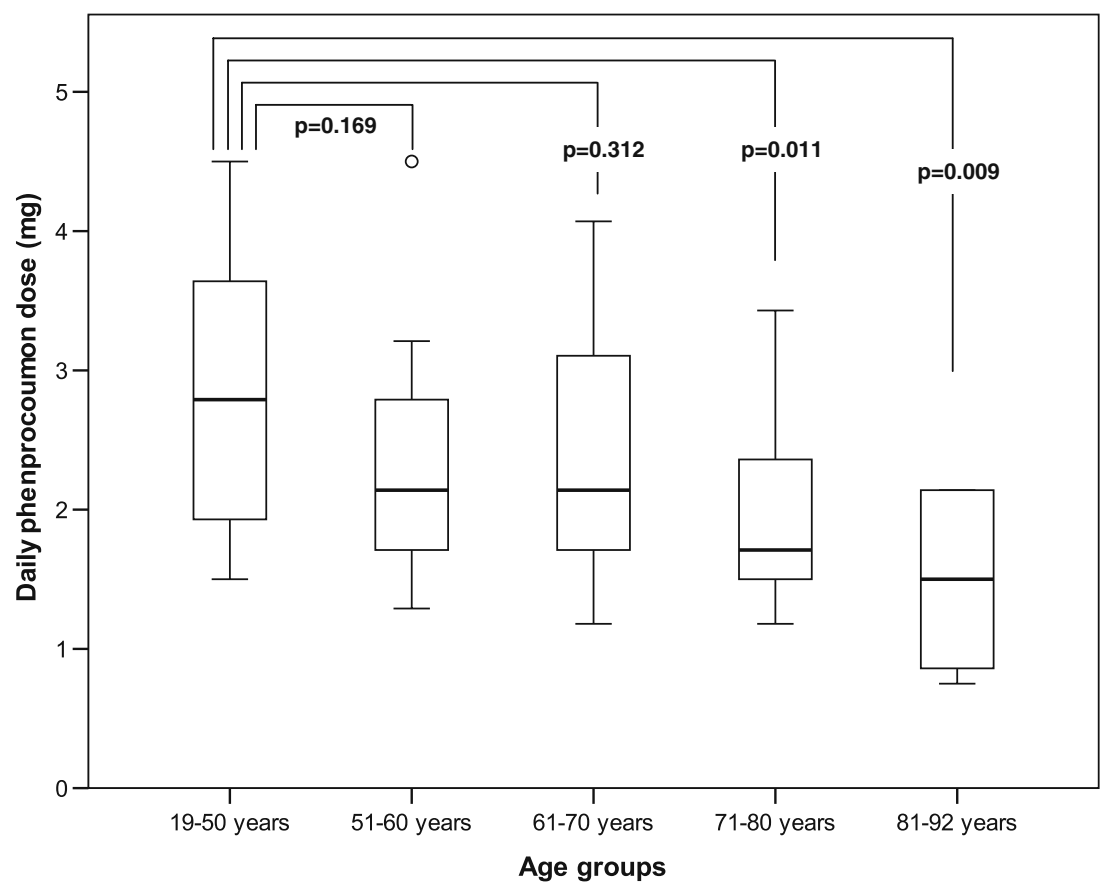

with similar findings of the role of $V K O R C 1$ in other coumarins such as warfarin and acenocoumarol $[8,9,32$, 33].

We did not detect an effect of $C Y P 2 C 9$ on phenprocoumon maintenance doses. This is in accordance with the studies of Hummers-Pradier et al. [34] and Visser et al. [35], who found no association between $C Y P 2 C 9$ variant alleles and phenprocoumon maintenance dose requirements in 185 and 173 outpatients respectively. However, Schalekamp et al. observed a $3.7-\mathrm{mg}$ lower weekly phenprocoumon steadystate dose for $C Y P 2 C 9^{*} 2$ carriers and a 4.4-mg lower weekly dose for $C Y P 2 C 9 * 3$ carriers compared with wild-type carriers [36]. These differences may be due to the larger cohort $(n=284)$ with a higher number of CYP2C $9 * 2$ and especially $* 3$ carriers in their study [36].

Somewhat surprising was the finding that $C Y P 2 C 9$ haplotypes affected the phenprocoumon plasma concentrations. Pharmacokinetic factors such as the CYP2C9 genotype are expected to alter the dose requirements, but not the plasma levels necessary to provide a therapeutic INR. However, we measured the total concentration of plasma phenprocoumon that might not be linearly translated into INR values. It would be interesting to see whether the concentrations of unbound phenprocoumon and Sphenprocoumon, which has a higher anticoagulant potency than the R-enantiomer [12], are also associated with the CYP2C9 genotype.

We did not find a substantial role for the gene variants CYP4F2 c. $1297 \mathrm{G}>\mathrm{A}, C A L U$ c. $* 4 \mathrm{~A}>\mathrm{G}, E P H X 1$ c. $337 \mathrm{~T}>\mathrm{C}$, $F 7 \quad$ c. $-402 \mathrm{G}>$ A, $F 7 \quad$ c. $-401 \mathrm{G}>\mathrm{T}, P R O C \quad$ c. $-228 \mathrm{C}>\mathrm{T}$ and $P R O C$ c. $-215 \mathrm{G}>\mathrm{A}$ as determinants of total phenprocoumon plasma concentrations or phenprocoumon dose variability. The inclusion of these SNPs into the regression equation for estimation of daily phenprocoumon doses did not improve the predictive value of this model.

In contrast, clinical factors such as age, height and BMI significantly contributed to the variability of phenprocoumon doses and phenprocoumon plasma concentrations

Table 4 Model of best fit in multiple linear regression analysis for mean daily phenprocoumon doses. Prior to analysis, square root transformation of daily phenprocoumon doses was performed. Dummy variables were created for VKORC1 genotypes with VKROC1 c.-1639GA as the reference group

\begin{tabular}{lllll}
\hline Genotype & $\mathrm{R}^{2}$ after entry, $\%$ & Adjusted $\mathrm{R}^{2} *$ after entry, \% & Regression coefficient in final model & $p$ value in final model \\
\hline Intercept & & & 0.460 & $<0.001$ \\
VKORC1 c.-1639GG & 30.3 & & 0.238 & $<0.001$ \\
VKORC1 c.-1639AA & 39.3 & 37.6 & -0.271 & 0.004 \\
Height & 47.3 & 45.0 & 0.007 & 0.018 \\
Age & 51.4 & 48.6 & -0.004 & \\
\hline
\end{tabular}

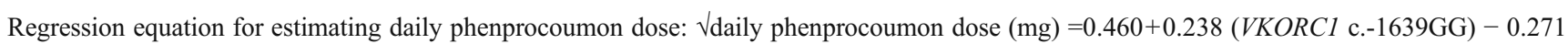
(VKORC1 c. $-1639 \mathrm{AA})+0.007$ (height) -0.004 (age) 


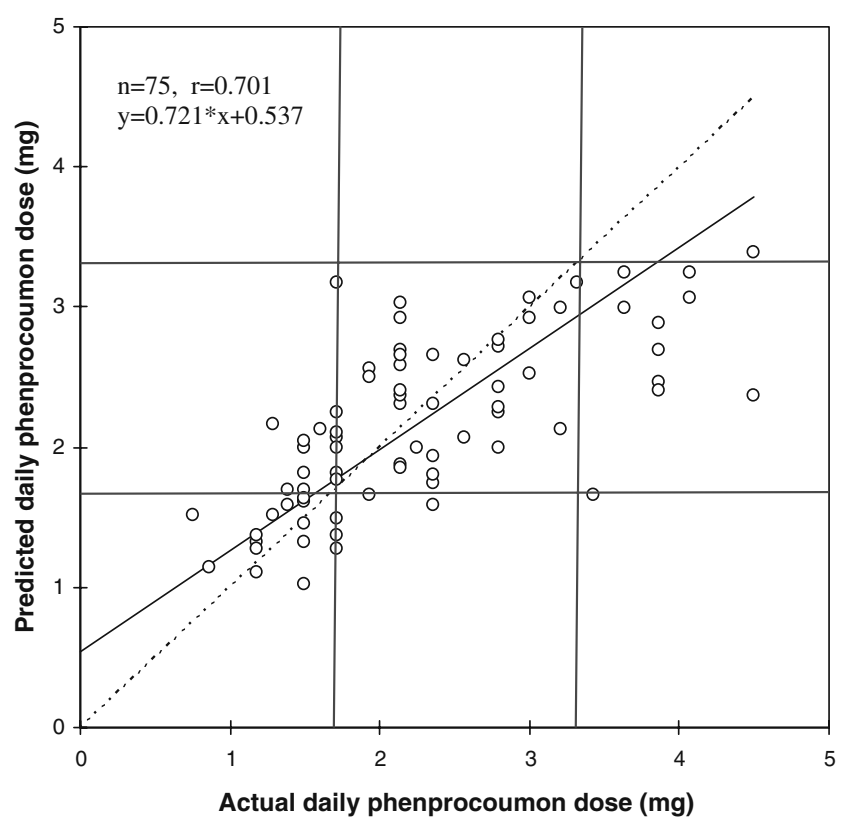

Fig. 3 Passing-Bablok regression for the calculated and actual daily phenprocoumon doses. The solid line is the line of regression, the dotted line is the line of identity

respectively. Age is a well-known predictor of coumarin dose response [11]. In our study, patients with ages 51-70, $71-80$ and $81-92$ years needed $23.3 \%, 38.7 \%$ and $46.2 \%$ lower daily phenprocoumon doses compared with younger patients. Concomitant medication and the resulting increased risk of drug interactions might predispose the elderly to higher coumarin sensitivity [37]. However, although the number of concomitant drugs was high in our study cohort, especially in the elderly (e.g. $52.6 \%$ of patients with ages of $71-$ 80 years had $\geq 5$ drugs), age was the only independent predictor of total plasma phenprocoumon concentrations and phenprocoumon dose requirements.

The potential of drugs to interfere with coumarins is mainly attributed to their interaction with the cytochrome P450 system [38]. The lack of association between concomitant medication and phenprocoumon might be due to its lower susceptibility to CYP2C9 inhibitors because CYP3A4 is also involved in its metabolism [15]. However, the categorisation of concomitant drug use in our study was rather crude, as we did not consider drug dosage and the potency of various drugs to interfere with phenprocoumon. It cannot be excluded that concomitant drugs are more relevant in other study populations with a higher number of patients on CYP3A4 substrates such as statins or potent CYP3A4 inhibitors, e.g. amiodarone. In our study, 15 patients were taking a statin, and 4 patients were taking amiodarone.

Because of the above observations, our final dosing equation for the prediction of the daily phenprocoumon dose was restricted to VKORCl, age and height, as these parameters alone accounted for $48.6 \%$ of daily phenprocoumon dose variability. A pharmacokinetic-pharmacodynamic model that incorporated the effects of VKORC1 c.1639, CYP2C9, age and BMI explained $52.8 \%$ of the drug plasma concentration variability.

The explanation of $50 \%$ of the total variability of the daily phenprocoumon maintenance dose is not sufficient to predict the exact maintenance dose in the individual patient. However, dosing equations such as those presented in this paper may help to identify subjects requiring low, intermediate, or high daily phenprocoumon doses. Pharmacogenomicbased dosing equations could reduce the time needed to find the adequate individual daily phenprocoumon dose and might help to avoid over-anticoagulation, especially in the early phase of phenprocoumon therapy. Moreover, pharmacogenomics might help to identify subjects more susceptible to drug interactions with phenprocoumon.

Our study is underpowered to detect factors with only a minor effect on phenprocoumon dose variability. However, our results are in line with genome-wide association studies that showed that $V K O R C 1$ and $C Y P 2 C 9$ may be considered the main pharmacogenetic predictors of coumarin dose requirements and demonstrated that common SNPs with substantial effects on coumarin dose requirements are unlikely to be discovered outside of the VKORCl and CYP2C9 genes [39, 40]. More sophisticated models integrating a large number of SNPs and other factors with minor influence might be necessary for the exact prediction of phenprocoumon maintenance doses, but might not be feasible and cost-effective in clinical routine. Thus, a
Table 5 Model of best fit in multiple linear regression analysis for phenprocoumon plasma concentrations. Dummy variables were created for VKORC1 genotypes (VKROC1 c. $-1639 \mathrm{GA}=$ reference group) and $C Y P 2 C 9(C Y P 2 C 9 * 1 / * 1=$ reference group)

\begin{tabular}{lllll}
\hline Genotype & $\begin{array}{l}\mathrm{R}^{2} \text { after } \\
\text { entry, } \%\end{array}$ & $\begin{array}{l}\text { Adjusted } \mathrm{R}^{2 *} \\
\text { after entry, } \%\end{array}$ & $\begin{array}{l}\text { Regression coefficient } \\
\text { in final model }\end{array}$ & $\begin{array}{l}p \text { value in } \\
\text { final model }\end{array}$ \\
\hline Intercept & & & 3.968 & \\
VKORC1 c.-1639GG & 29.6 & & 0.509 & 0.001 \\
VKORC1 c.-1639AA & 40.0 & 38.3 & -0.690 & $<0.001$ \\
Age & 46.2 & 43.9 & -0.009 & 0.038 \\
CYP2C $9 * 3$ & 49.4 & 46.5 & 0.507 & 0.012 \\
CYP2C $9 * 2$ & 53.3 & 49.9 & 0.366 & 0.014 \\
$\sqrt{\mathrm{BMI}}$ & 56.6 & 52.8 & -0.321 & 0.026 \\
\hline
\end{tabular}


combination of standardised protocols for the start-up phenprocoumon therapy with crude estimations of the presumed maintenance doses based on relatively few parameters might be a pragmatic solution to the problem.

Our study has several limitations. We applied the prediction formula to all patients and showed a good correlation between the estimated and the given maintenance dose. However, no data from an independent prospective study were available to validate our dosing formula.

Recruiting only patients with stable phenprocoumon doses might have excluded a substantial subgroup of patients. However, the definition of stable maintenance doses in our study was a bit more liberal compared with other studies $[19,21]$. The inclusion of patients with unstable phenprocoumon doses would have increased the interindividual dose variability and has the potential to reduce the predictive value of regression models.

In our study, $25 \%$ of patients did not report on alcohol habits. Data on alcohol consumption from questionnaires may be unreliable as patients with heavy alcohol consumption might prefer not to report their drinking habits. Adding biomarkers such as carbohydrate-deficient transferrin or phosphatidylethanol to in-depth interviews might have been better tools to classify alcohol consumption [41, 42].

Despite the fact that many dosing equations have been developed to predict warfarin dose requirements, the benefit of pharmacogenetic-guided coumarin therapy remains a matter of controversy [43]. Some studies indicate that early INR and standardised dose adaptation can cover for the genetic information, which is mainly only significant in the early phase of therapy $[44,45]$. The impact of genotypeguided dosing formulas might differ among coumarins with markedly different pharmacokinetic characteristics. Our study provides a rationale for a rough prediction of phenprocoumon maintenance doses. Prospective clinical trials are warranted to investigate whether genotype-guided dosing formulas are superior to standardised dosing protocols for improved safety and cost-effectiveness of coumarin therapy.

Acknowledgement The authors thank Dr. M. Glowatzki, SPSS $\mathrm{GmbH}$, Munich, for statistical advice.

Conflict of interest The authors declare that they have no conflict of interest.

\section{References}

1. Pirmohamed M, James S, Meakin S, Green C, Scott AK, Walley TJ, Farrar K, Park BK, Breckenridge AM (2004) Adverse drug reactions as cause of admission to hospital: prospective analysis of 18820 patients. BMJ 329:15-19
2. Patel KJ, Kedia MS, Bajpai D, Mehta SS, Kshirsagar NA, Gogtay NJ (2007) Evaluation of the prevalence and economic burden of adverse drug reactions presenting to the medical emergency department of a tertiary referral centre: a prospective study. BMC Clin Pharmacol 7:8

3. Palareti G, Leali N, Coccheri S, Poggi M, Manotti C, D’Angelo A, Pengo V, Erba N, Moia M, Ciavarella N, Devoto G, Berrettini M, Musolesi S (1996) Bleeding complications of oral anticoagulant treatment: an inception-cohort, prospective collaborative study (ISCOAT). Italian study on complications of oral anticoagulant therapy. Lancet 348:423-428

4. Ansell J, Hirsh J, Hylek E, Jacobson A, Crowther M, Palareti G, American College of Chest Physicians (2008) Pharmacology and management of the vitamin $\mathrm{K}$ antagonists: American College of Chest Physicians evidence-based clinical practice guidelines (8th edition). Chest 133:160S-198S

5. Oldenburg J, Bevans CG, Müller CR, Watzka M (2006) Vitamin $\mathrm{K}$ epoxide reductase complex subunit 1 (VKORC1): the key protein of the vitamin K cycle. Antioxid Redox Signal 8:347-353

6. Oldenburg J, Bevans CG, Fregin A, Geisen C, Müller-Reible C, Watzka M (2007) Current pharmacogenetic developments in oral anticoagulation therapy: the influence of variant VKORC1 and CYP2C9 alleles. Thromb Haemost 98:570-578

7. Geisen C, Watzka M, Sittinger K, Steffens M, Daugela L, Seifried E, Müller CR, Wienker TF, Oldenburg J (2005) VKORC1 haplotypes and their impact on the inter-individual and interethnical variability of oral anticoagulation. Thromb Haemost 94:773-779

8. Wang D, Chen H, Momary KM, Cavallari LH, Johnson JA, Sadée W (2008) Regulatory polymorphism in vitamin K epoxide reductase complex subunit 1 (VKORC1) affects gene expression and warfarin dose requirement. Blood 112:1013-1021

9. Limdi NA, Wadelius M, Cavallari L, Eriksson N, Crawford DC, Lee MT, Chen CH, Motsinger-Reif A, Sagreiya H, Liu N, Wu AH, Gage BF, Jorgensen A, Pirmohamed M, Shin JG, Suarez-Kurtz G, Kimmel SE, Johnson JA, Klein TE, Wagner MJ (2010) Warfarin pharmacogenetics: a single VKORC1 polymorphism is predictive of dose across three racial groups. Blood 115:3827-3834

10. Lubitz SA, Scott SA, Rothlauf EB, Agarwal A, Peter I, Doheny D, Van Der Zee S, Jaremko M, Yoo C, Desnick RJ, Halperin JL (2010) Comparative performance of gene-based warfarin dosing algorithms in a multiethnic population. J Thromb Haemost 8:1018-1026

11. Puehringer H, Loreth RM, Klose G, Schreyer B, Krugluger W, Schneider B, Oberkanins C (2010) VKORC1 -1639G $>$ A and CYP2C $9 * 3$ are the major genetic predictors of phenprocoumon dose requirement. Eur J Clin Pharmacol 66:591-598

12. Stehle S, Kirchheiner J, Lazar A, Fuhr U (2008) Pharmacogenetics of oral anticoagulants: a basis for dose individualization. Clin Pharmacokinet 47:565-594

13. Beinema M, Brouwers JR, Schalekamp T, Wilffert B (2008) Pharmacogenetic differences between warfarin, acenocoumarol and phenprocoumon. Thromb Haemost 100:1052-1057

14. Miners JO, Birkett DJ (1998) Cytochrome P4502C9: an enzyme of major importance in human drug metabolism. Br J Clin Pharmacol 45:525-538

15. Ufer M, Svensson JO, Krausz KW, Gelboin HV, Rane A, Tybring G (2004) Identification of cytochromes P450 2C9 and 3A4 as the major catalysts of phenprocoumon hydroxylation in vitro. Eur $\mathrm{J}$ Clin Pharmacol 60:173-182

16. Caldwell MD, Awad T, Johnson JA, Gage BF, Falkowski M, Gardina P, Hubbard J, Turpaz Y, Langaee TY, Eby C, King CR, Brower A, Schmelzer JR, Glurich I, Vidaillet HJ, Yale SH, Qi Zhang K, Berg RL, Burmester JK (2008) CYP4F2 genetic variant alters required warfarin dose. Blood 111:4106-4112 
17. Borgiani P, Ciccacci C, Forte V, Sirianni E, Novelli L, Bramanti P, Novelli G (2009) CYP4F2 genetic variant (rs2108622) significantly contributes to warfarin dosing variability in the Italian population. Pharmacogenomics 10:261-266

18. Takeuchi F, McGinnis R, Bourgeois S, Barnes C, Eriksson N, Soranzo N, Whittaker P, Ranganath V, Kumanduri V, McLaren W, Holm L, Lindh J, Rane A, Wadelius M, Deloukas P (2009) A genome-wide association study confirms VKORC1, CYP2C9, and CYP4F2 as principal genetic determinants of warfarin dose. PLoS Genet 5:e1000433

19. Vecsler M, Loebstein R, Almog S, Kurnik D, Goldman B, Halkin $\mathrm{H}$, Gak E (2006) Combined genetic profiles of components and regulators of the vitamin K-dependent gamma-carboxylation system affect individual sensitivity to warfarin. Thromb Haemost 95:205-211

20. González-Conejero R, Corral J, Roldán V, Ferrer F, SánchezSerrano I, Sánchez-Blanco JJ, Marín F, Vicente V (2007) The genetic interaction between VKORC1 c1173t and calumenin a29809g modulates the anticoagulant response of acenocoumarol. J Thromb Haemost 5:1701-1706

21. Shikata E, Ieiri I, Ishiguro S, Aono H, Inoue K, Koide T, Ohgi S, Otsubo K (2004) Association of pharmacokinetic (CYP2C9) and pharmacodynamic (factors II, VII, IX, and X; proteins S and C; and gamma-glutamyl carboxylase) gene variants with warfarin sensitivity. Blood 103:2630-2635

22. Kimura R, Miyashita K, Kokubo Y, Akaiwa Y, Otsubo R, Nagatsuka K, Otsuki T, Okayama A, Minematsu K, Naritomi H, Honda S, Tomoike H, Miyata T (2007) Genotypes of vitamin K epoxide reductase, gamma-glutamyl carboxylase, and cytochrome P450 2C9 as determinants of daily warfarin dose in Japanese patients. Thromb Res 120:181-186

23. Loebstein R, Vecsler M, Kurnik D, Austerweil N, Gak E, Halkin H, Almog S (2005) Common genetic variants of microsomal epoxide hydrolase affect warfarin dose requirements beyond the effect of cytochrome P450 2C9. Clin Pharmacol Ther 77:365-372

24. Wadelius M, Chen LY, Downes K, Ghori J, Hunt S, Eriksson N, Wallerman O, Melhus H, Wadelius C, Bentley D, Deloukas $P$ (2005) Common VKORC1 and GGCX polymorphisms associated with warfarin dose. Pharmacogenomics J 5:262270

25. D'Ambrosio RL, D'Andrea G, Cappucci F, Chetta M, Di Perna P, Brancaccio V, Grandone E, Margaglione M (2004) Polymorphisms in factor II and factor VII genes modulate oral anticoagulation with warfarin. Haematologica 89:1510-1516

26. Wadelius M, Chen LY, Eriksson N, Bumpstead S, Ghori J, Wadelius C, Bentley D, McGinnis R, Deloukas P (2007) Association of warfarin dose with genes involved in its action and metabolism. Hum Genet 121:23-34

27. Pautas E, Moreau C, Gouin-Thibault I, Golmard JL, Mahé I, Legendre C, Taillandier-Hériche E, Durand-Gasselin B, Houllier AM, Verrier P, Beaune P, Loriot MA, Siguret V (2010) Genetic factors (VKORC1, CYP2C9, EPHX1, and CYP4F2) are predictor variables for warfarin response in very elderly, frail inpatients. Clin Pharmacol Ther 87:57-64

28. Lee MT, Chen CH, Chou CH, Lu LS, Chuang HP, Chen YT, Saleem AN, Wen MS, Chen JJ, Wu JY, Chen YT (2009) Genetic determinants of warfarin dosing in the Han-Chinese population. Pharmacogenomics 10:1905-1913

29. Cadamuro J, Dieplinger B, Felder T, Kedenko I, Mueller T, Haltmayer M, Patsch W, Oberkofler H (2010) Genetic determinants of acenocoumarol and phenprocoumon maintenance dose requirements. Eur J Clin Pharmacol 66:253-260

30. Schulz M, Schmoldt A (2003) Therapeutic and toxic blood concentrations of more than 800 drugs and other xenobiotics. Pharmazie 58:447-474
31. Luxembourg B, Schneider K, Sittinger K, Toennes SW, Seifried E, Lindhoff-Last E, Oldenburg J, Geisen C. Impact of pharmacokinetic (CYP2C9) and pharmacodynamic (VKORC1, F7, GGCX, $C A L U, E P H X 1)$ gene variants on the initiation and maintenance phases of phenprocoumon therapy. Thromb Haemost. doi:10.1160/TH10-03-0194.

32. Bodin L, Verstuyft C, Tregouet DA, Robert A, Dubert L, FunckBrentano C, Jaillon P, Beaune P, Laurent-Puig P, Becquemont L, Loriot MA (2005) Cytochrome P450 2C9 (CYP2C9) and vitamin $\mathrm{K}$ epoxide reductase (VKORC1) genotypes as determinants of acenocoumarol sensitivity. Blood 106:135-140

33. Markatos CN, Grouzi E, Politou M, Gialeraki A, Merkouri E, Panagou I, Spiliotopoulou I, Travlou A (2008) VKORC1 and CYP2C9 allelic variants influence acenocoumarol dose requirements in Greek patients. Pharmacogenomics 9:16311638

34. Hummers-Pradier E, Hess S, Adham IM, Papke T, Pieske B, Kochen MM (2003) Determination of bleeding risk using genetic markers in patients taking phenprocoumon. Eur J Clin Pharmacol $59: 213-219$

35. Visser LE, van Vliet M, van Schaik RH, Kasbergen AA, De Smet PA, Vulto AG, Hofman A, van Duijn CM, Stricker BH (2004) The risk of overanticoagulation in patients with cytochrome $\mathrm{P} 450$ CYP2C $9 * 2$ or CYP2C9*3 alleles on acenocoumarol or phenprocoumon. Pharmacogenetics 14:27-33

36. Schalekamp T, Oosterhof M, van Meegen E, van Der Meer FJ, Conemans J, Hermans M, Meijerman I, de Boer A (2004) Effects of cytochrome P450 2C9 polymorphisms on phenprocoumon anticoagulation status. Clin Pharmacol Ther 76:409417

37. Husted S, Andreasen F (1977) The influence of age on the response to anticoagulants. Br J Clin Pharmacol 4:559-565

38. Wilkinson GR (2005) Drug metabolism and variability among patients in drug response. N Engl J Med 352:2211-2221

39. Teichert M, Eijgelsheim M, Rivadeneira F, Uitterlinden AG, van Schaik RH, Hofman A, De Smet PA, van Gelder T, Visser LE, Stricker BH (2009) A genome-wide association study of acenocoumarol maintenance dosage. Hum Mol Genet 18:37583768

40. Cooper GM, Johnson JA, Langaee TY, Feng H, Stanaway IB, Schwarz UI, Ritchie MD, Stein CM, Roden DM, Smith JD, Veenstra DL, Rettie AE, Rieder MJ (2008) A genome-wide scan for common genetic variants with a large influence on warfarin maintenance dose. Blood 112:1022-1027

41. Hannuksela ML, Liisanantti MK, Nissinen AE, Savolainen MJ (2007) Biochemical markers of alcoholism. Clin Chem Lab Med 45:953-961

42. Hartmann S, Aradottir S, Graf M, Wiesbeck G, Lesch O, Ramskogler K, Wolfersdorf M, Alling C, Wurst FM (2007) Phosphatidylethanol as a sensitive and specific biomarker: comparison with gamma-glutamyl transpeptidase, mean corpuscular volume and carbohydrate-deficient transferrin. Addict Biol $12: 81-84$

43. Kangelaris KN, Bent S, Nussbaum RL, Garcia DA, Tice JA (2009) Genetic testing before anticoagulation? A systematic review of pharmacogenetic dosing of warfarin. J Gen Intern Med 24:656-664

44. Ferder NS, Eby CS, Deych E, Harris JK, Ridker PM, Milligan PE, Goldhaber SZ, King CR, Giri T, McLeod HL, Glynn RJ, Gage BF (2010) Ability of VKORC1 and CYP2C9 to predict therapeutic warfarin dose during the initial weeks of therapy. J Thromb Haemost 8:95-100

45. Li C, Schwarz UI, Ritchie MD, Roden DM, Stein CM, Kurnik D (2009) Relative contribution of CYP2C9 and VKORC1 genotypes and early INR response to the prediction of warfarin sensitivity during initiation of therapy. Blood 113:3925-3930 